\title{
ANALYSIS MIXED LAYER ASPHALT SURFACE AS Asbuton AC-WC CHARACTERISTICS OF MARSHALL
}

\author{
Huda Alfian Aunur, HASYIR \\ Faculty of Engineering, Narotama University, Surabaya, Indonesia \\ alfianfidi@gmail.com \\ Sapto Budi, WASONO \\ Faculty of Engineering, Narotama University, Surabaya, Indonesia \\ sapto.budy@narotama.ac.id
}

\begin{abstract}
Natural asphalt is asphalt obtained somewhere in nature, and can be used as obtained or with little processing. No natural asphalt obtained in the mountains like asphalt in Buton island called Asbuton. Asphalt Buton island is a mixture of bitumen material with other mineral materials in the form of rocks. Because asbuton is so sajaa material found in nature, the levels of bitumen dikandungnyaa greatly varies from low to high. To overcome this, then asbuton began to be produced in various forms at the processing plant asbuton. To reduce the use of natural asphalt eat more steps to do research on utilizing asbuton with the composition $6 \%, 8 \%, 10 \%$. The purpose of this study is 1.) Determine the material characteristics LGA Asbuton can meet the specifications of Highways in 2018 on a mix of AC-WC 2.) Determine the value of Optimum Asphalt Content on asphalt concrete AC-WC (Asphalt Concrete - Wearing Course) with extra material LGA Asbuton 3.) Knowing how the performance of asphalt concrete AC-WC with additional material and bitumen 60/70 Asbuton terms of Marshall Test. The study was conducted with an experimental method through laboratory testing. The expected benefits of this research is the discovery of optimizing the use of Asbuton for at the time of execution of the work of new road construction or road maintenance and provide alternative natural aggregate material consumption to a minimum. The test results for the optimum bitumen content KAO on the composition 1 Asbuton 6\% with a variation of bitumen (5.05\% 5.55\% 6.05\% 6.55\% 7.05\%) of the chart can be found KAO Marshall 6.2\%. Composition 2 Asbuton $8 \%$ with a variation of asphalt (5.0\% 5.5\% 6.0\% 6.5\% 7.0\%) on the graph can be found KAO Marshall $6.3 \%$. Composition 3 Asbuton 10\% with a variation of asphalt (5.0\% 5.5\% 6.0\% 6.5\% 7.0\%) on the graph can be found KAO Marshall $6.4 \%$. Variations in the composition of $6 \%, 8 \%$ and $10 \%$ meet all the requirements of the properties of hot asphalt mix can specification of Highways in 2018.
\end{abstract}

Keywords asphalt mixture, asbuton, bitumen pen 60/70, ac-wc, flexible pavements

\section{INTRODUCTION}

Asphalt concrete pavement is a type comprising a mixture of aggregate and bitumen with or without additives. The temperature for mixing based on the type of bitumen to be used. If used asphalt cement, the mixing temperature is generally between $145^{\circ}-155^{\circ} \mathrm{C}$, so-called hot mix asphalt concrete. There are seven characteristics that should be possessed by asphalt concrete is its stability, durability, pliability or flexibility, resistance to fatigue, surface roughness or shear resistance, waterproof and ease of implementation. Seventh properties of asphalt concrete mixtures is not possible can be satisfied by a mixture. Asphalt concrete consists of three (3) kinds of layers, namely Laston Lapis Aus (ConcreteAsphalt Wearing Course or AC-WC), 
Table 1The content of BGA and LGA Asbuton of Results Ektrasi

\begin{tabular}{|l|c|c|c|}
\hline \multicolumn{1}{|c|}{ property } & unit & Kabungka & Lawele \\
\hline Asphalt Content & \%weight & 20 & 30.8 \\
\hline $\begin{array}{l}\text { Penetration }\left(25^{\circ} \mathrm{C}, 100\right. \\
\text { gram, 5 seconds) }\end{array}$ & $0.1 \mathrm{~mm}$ & 40 & 36 \\
\hline Flabby point & ${ }^{\circ} \mathrm{C}$ & 101 & 59 \\
\hline Flash point & ${ }^{\circ} \mathrm{C}$ & - & 198 \\
\hline Daktalitas $\left(25^{\circ} \mathrm{C}, 5 \mathrm{~cm} / \mathrm{min}\right)$ & $\mathrm{cm}$ & $<140$ & $>140$ \\
\hline specific Gravity & & 1046 & 1037 \\
\hline Penetration $(\mathrm{LOH})$ & \%weight & & 94 \\
\hline Flabby point $(\mathrm{LOH})$ & ${ }^{\circ} \mathrm{C}$ & & 62 \\
\hline Loss on heating $\left(163{ }^{\circ} \mathrm{C}, 5\right.$ hour) & \%weight & & $0: 31$ \\
\hline solubility trichloroethvlene & \%weight & & 99.6 \\
\hline
\end{tabular}

Source: Research Thesis (Heddy.R, 2012)

Generally the type of asphalt that is often used on road work in Indonesia using asphalt Pen 60/70, but the amount of asphalt Pen 60/70 more years of decreases. On the other hand the existence of asbuton in Indonesia is quite a lot that can be utilized as an alternative to asphalt mixture can then be expected to cope with damage to roads. Therefore there is need for a penilitian on Asphalt Mixture Analysis As Asbuton with Asphalt Surface Characteristics Ac-wc Against Marshall.

\section{LITERATURE REVIEW}

Natural asphalt is only found in two places in the world, namely in Buton Island in Indonesia and Trinidad Tobago in Central America. Distribution of natural asphalt in Buton Island alone reached 700 million tons, which is recognized as the largest natural bitumen deposits in the world, which is about $80 \%$ of total world reserves of natural bitumen.

Buton asphalt have been found since 1924 in Buton island, but only began to be used for paving since 1926. Currently, Buton asphalt is also used for the improvement and development of infrastructure, roads, and bridges in the Buton as one priority in RPJMD ( Regional Medium-Term Development plan) Buton years 2012-2017. Based on existing data, asbuton have a deposit of around 677 million tonnes.

Asphalt created from layers minyaak in the bowels of the earth trapped in the layers of the earth. The mixture contained the oil will drift up and mixed with soil and rocks in the upper layer. Petroleum is in the inner layer that is topped with rocks and soil. The trapped oil will rise to the rocks and soil. Buton is an area of the fault that contain petroleum Buton asphalt. Asphalt of this type are found in the Lawele on the island of Buton, Southeast Sulawesi. Buton asphalt can be found to a depth of 1,000 meters down, while new oil asphalt can ditemukaan after a depth of 3,800 meters. If the bitumen is separated from petroleum, is expected to be obtained haasil one ton of oil on each 5 tons of asphalt were processed.

\section{Drafting material mixture Asbuton \\ Aggregate}

Coarse aggregate fraction that is retained on sieve \# $8(2,36 \mathrm{~mm})$, coarse aggregate functions are as follows:

1. Provide stability of the mixture of the condition of the interlocking of each - each coarse aggregate and of the frictional resistance to a displacement action. 
2. Stability is determined by the shape and surface texture of coarse aggregate (cubes and coarse). Fine aggregate fraction, namely through sieve \# 8 and restrained \# 200fungsi fine aggregate are as follows:

3. Increase the stability of the mixture to solidify the interlocking nature of the coarse aggregate and also to reduce the air cavity of coarse aggregate. The more rough surface texture of fine aggregate will increase the stability of the mixture and add surface roughness.

4. Fine aggregate at \# 8 to \# 30 is important in providing a good roughness for a vehicle on the surface of Gap Graded aspal.Pada, fine aggregates on the \# 8 to \# 30 is reduced in order to obtain an adequate air cavity for a certain amount of asphalt, so that the surface of the Gap Graded tend to be smooth.

Aggregate determine the amount of cavities or pores that may occur in the aggregate mix. Aggregate mixture consisting of an aggregate of the same size will be hollow or porous, because there were a smaller aggregate to fill the cavities that occur. Conversely, if the aggregate mixture distributed from small to large-sized aggregates evenly, then cavities or pores that occurred a little.

\section{Asphalt}

Asphalt is an element hidokarbon very complex, very difficult to separate the molecules that make up the asphalt. Besides, each source of petroleum produce different molecular composition. Asphalt composition comprised of asphaltenes and metanes. Asphaltenes, a material that is black or dark brown insoluble in heptane. Maltenes insoluble in heptane, a viscous liquid consisting of resins and oils. Resin is a viscous liquid that is yellow or dark brown are on the adhesion properties of asphalt is the easy part is lost or reduced during the service road (Sukirman, 1999).

\section{Marshal Test for Asphalt Concrete}

The strength of concrete is hard concrete ability to withstand the compressive force in per unit surface area of the concrete. Theoretically, the compressive strength of concrete is influenced by the strength of its components

Density (density)

Density is the ratio between the dry weight of the specimen to the weight of water in the same volume. The density can be calculated using the equation:

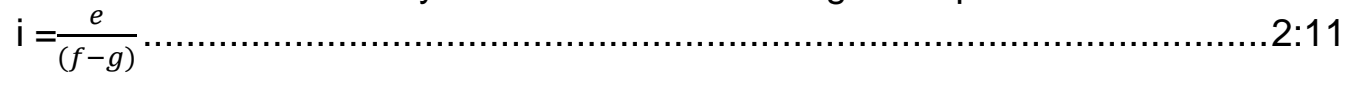

Information:

$$
\begin{aligned}
& i=\text { density }(g / \mathrm{cm} 3) \\
& e=\text { dry weight }(g) \\
& f=\text { weight in the dry state of the surface saturation }(g) \\
& g=\text { weight in water }(g) \\
& (F-g)=\text { bulk volume }(\mathrm{cm} 3)
\end{aligned}
$$

Voids in the mixture (void in mix)

Mineral aggregate in the cavity or cavities between the aggregate grains are contained in the cavity volume between the aggregate particles of a mixture of pavement that has been compacted, the air voids and effective asphalt content volume, expressed in percent of the total volume of the test object. 
Cavity filled with asphalt (void filled by asphalt)

Cavity filled with asphalt or a void filled by asphalt (VFA) is the ratio between the cavities are filled with asphalt to the volume of the test object.Sukirman (2003)mention the percentage of pores between the grains are filled with asphalt aggregates called VFA. So VFA is part of the VMA filled by asphalt, excluding bitumen absorbed by each grain aggregate. Asphalt that fills the pores serves to wrap a grain aggregate in dense asphalt concrete, or in other words the VFA is the percentage of dense asphalt concrete volume that became a movie or asphalt blankets.

Stability (stability)

Stability is the ability of a pavement receives the traffic load without changes in fixed form like waves, grooves, or bleeding (Sukirman, 2003). Values obtained from the readout dial stability Marshall stability and then be multiplied by the calibration and correction factor of the test specimen.

\section{RESEARCH METHODS}

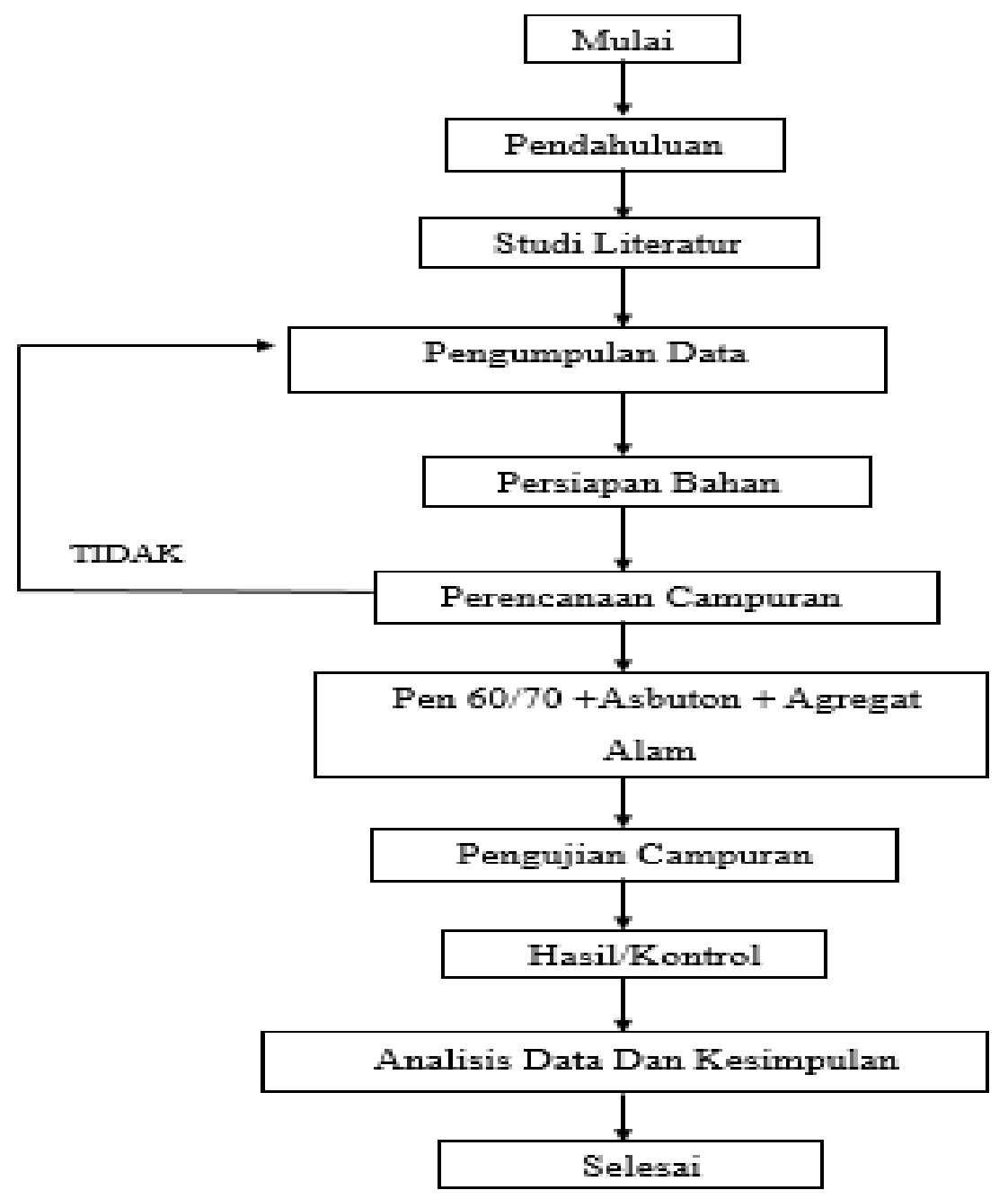

Figure 1 : Flowchart of Research 


\section{RESULTS AND DISCUSSION}

\section{The composition of the mixture gradation RAP $25 \%, 30 \%, 35 \%$}

Coarse aggregate, aggregate medium, fine aggregate and Asbuton used to go into the envelope gradation according Highways 2018 General Specifications for hot asphalt mixture smooth gradations, required the addition of new aggregate. The calculation of the aggregate composition is done by trial and error to obtain a composition that meets the requirements. Asbuton composition calculation, the aggregate coarse, medium and fine aggregate aggregate for the composition 1 can be seen in Table 4.5. While the calculation for the composition of the second and third compositions can be found in the appendix. From these calculations compositions that meet the requirements are:

1. Composition 1: Asbuton LGA $6.0 \%, 13 \%$ coarse aggregate, $39 \%$ of the aggregate being, $42 \%$ of fine aggregate

2. Composition 2: LGA Asbuton $8.0 \%, 15 \%$ coarse aggregate, $36 \%$ of the aggregate medium, $41 \%$ fine aggregate

3. Composition 3: Asbuton LGA $10.0 \%, 17 \%$ coarse aggregate, $33 \%$ of the aggregate medium, $40 \%$ fine aggregate

Table 4.1. Composition Calculations 1

\begin{tabular}{|c|c|c|c|c|c|c|c|c|c|c|c|}
\hline \multicolumn{2}{|l|}{ DESCRIPTION } & \multicolumn{10}{|c|}{ SIZE FILTER } \\
\hline \multirow{2}{*}{\multicolumn{2}{|c|}{$\begin{array}{l}\text { inches } \\
\mathrm{mm}\end{array}$}} & $3 / 4 "$ & $1 / 2 "$ & $3 / 8 "$ & $\# 4$ & $\# 8$ & $\# 16$ & \# 30 & $\# 50$ & $\# 100$ & \# 200 \\
\hline & & 19.0 & 12.5 & 9.5 & 4.75 & 2.36 & 1.18 & 0,600 & .300 & .150 & 0.075 \\
\hline \multicolumn{2}{|c|}{$\begin{array}{l}\text { Aggregate Gradation } \\
\text { Data }\end{array}$} & & & & & & & & & & \\
\hline \multicolumn{2}{|l|}{ - AGG Asbuton } & 100.00 & 97.08 & 91.93 & 68.15 & 44.48 & 31.56 & 23.34 & 16.37 & 10.44 & 6.27 \\
\hline \multicolumn{2}{|l|}{ - AGG rough } & 100.00 & 17.59 & 1.37 & 0.21 & 0.21 & 0.21 & 0.21 & 0.20 & 0.17 & 0.14 \\
\hline \multicolumn{2}{|l|}{ - AGG is being } & 100.00 & 100.00 & 83.36 & 16.47 & 1.55 & 0.51 & 0.43 & 0.40 & 0.34 & 0.19 \\
\hline \multicolumn{2}{|l|}{ - AGG smooth } & 100.00 & 100.00 & 100.00 & 99.70 & 84.77 & 57.01 & 39.79 & 27.85 & 19.07 & 11.40 \\
\hline \multicolumn{12}{|c|}{$\begin{array}{l}\text { The combination of } \\
\text { Aggregate } \\
\text { - Aggregate }\end{array}$} \\
\hline Asbuton & $6.0 \%$ & 30.0 & 29.1 & 27.6 & 20.4 & 13.3 & 9.5 & 7.0 & 4.9 & 3.1 & 1.9 \\
\hline - AGG rough & $13.0 \%$ & 5.0 & 0.9 & 0.1 & 0.0 & 0.0 & 0.0 & 0.0 & 0.0 & 0.0 & 0.0 \\
\hline - $A G G$ is being & $39.0 \%$ & 22.0 & 22.0 & 18.3 & 3.6 & 0.3 & 0.1 & 0.1 & 0.1 & 0.1 & 0.0 \\
\hline - AGG smooth & $42.0 \%$ & 42.0 & 42.0 & 42.0 & 41.9 & 35.6 & 23.9 & 16.7 & 11.7 & 8.0 & 4.8 \\
\hline total mix & $100.0 \%$ & 100.0 & 95.0 & 89.0 & 67.0 & 50.3 & 34.5 & 24.8 & 17.7 & 12.2 & 7.7 \\
\hline \multicolumn{12}{|l|}{$\begin{array}{l}\text { Ttitik } \\
\text { Control }\end{array}$} \\
\hline Maximum & & 100 & 100.0 & 90.0 & 69.0 & 53.0 & 40.0 & 30.0 & 22.0 & 15.0 & 9.0 \\
\hline Minimum & & 100 & 90.0 & 77.0 & 53.0 & 33.0 & 21.0 & 14.0 & 9.0 & 6.0 & 4.0 \\
\hline Ideal & & 100 & 95.0 & 81.0 & 61.5 & 46.1 & 35.8 & 26.6 & 18.8 & 12.0 & 7.0 \\
\hline
\end{tabular}




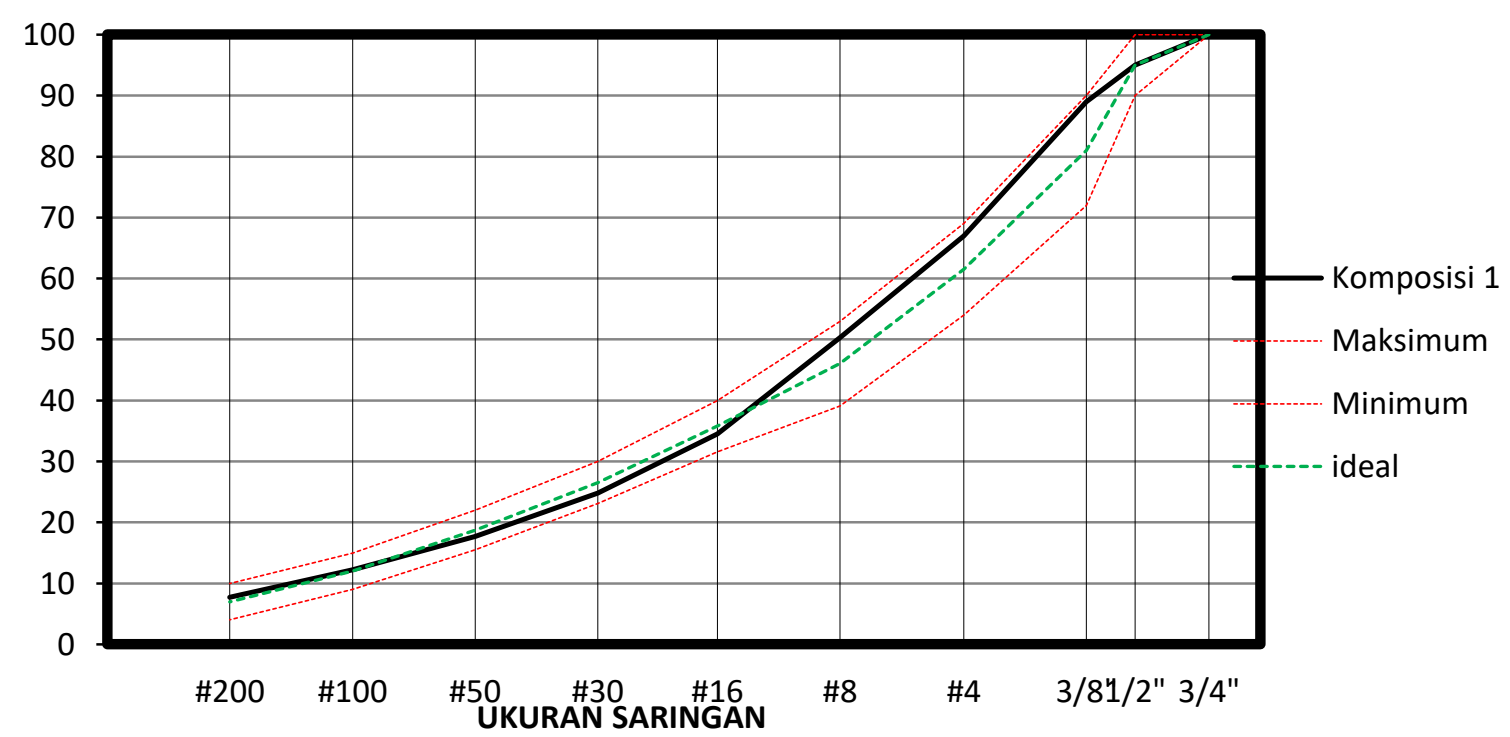

Figure 2. Envelope Gradient AC-WC (Source: Calculations layer Asbuton AC-WC + 6\%)

Furthermore, the calculation of bitumen content plan in accordance with the Planning Guidelines Asphalt Mixture Density Approach Absolute no. 025 / T / BM / 1999 Ministry of Public Works Highways. Calculation of Asphalt Content Composition Plan 1:

From Table 4.5 is obtained:

$$
\begin{array}{llll}
\% \mathrm{CA}= & (100-50,3) \%= & 49.7 \% \\
\% \mathrm{FA} & = & (50.3 \text { to } 7,7) \%= & 42.6 \% \\
\% \mathrm{FF} & = & 7.7 \% \\
\mathrm{~Pb} & =0.035 \times(\% \mathrm{CA})+0.045 \times(\% \mathrm{FA})+0.18 \times(\% \mathrm{FF})+\mathrm{K} \\
\mathrm{Pb} & =0,035 \times 0,045 \times 49.7 \%+42.6 \%+7.7 \%+0.18 \times 1 \\
\mathrm{~Pb} & =6.0451 \% \text { rounded to } 6.05 \% .
\end{array}
$$

Having obtained the asphalt content plan then the next planned Marshal specimen weighing 1,200 grams of a mixture of the test object Marshal. Asphalt content of this plan is the total binder content, so the new asphalt is added is the difference between bitumen content plans with bitumen content contained in the RAP. Composition RAP for $30 \%$ and $35 \%$ imposed the same as step study of the composition of $25 \%$ RAP.

\section{Testing Results Marshal recapitulation Asbuton 6\%, $8 \%$ and $10 \%$.}

From the test results mix hot asphalt of each composition used in this study, summarized the results in a graph for composition 1, composition 2 and composition 3 obtained Levels Asphalt Optimum (KAO) determined from combining the value of VIM, VMA, VFA, Stability, flow and Marshall Quotient (MQ) who get a grade interval of eligible asphalt. The determination of optimum bitumen content (OBC) was determined from the relationship of several parameters asphalt mix design testing AC-WC and Asbuton with the required standards. 

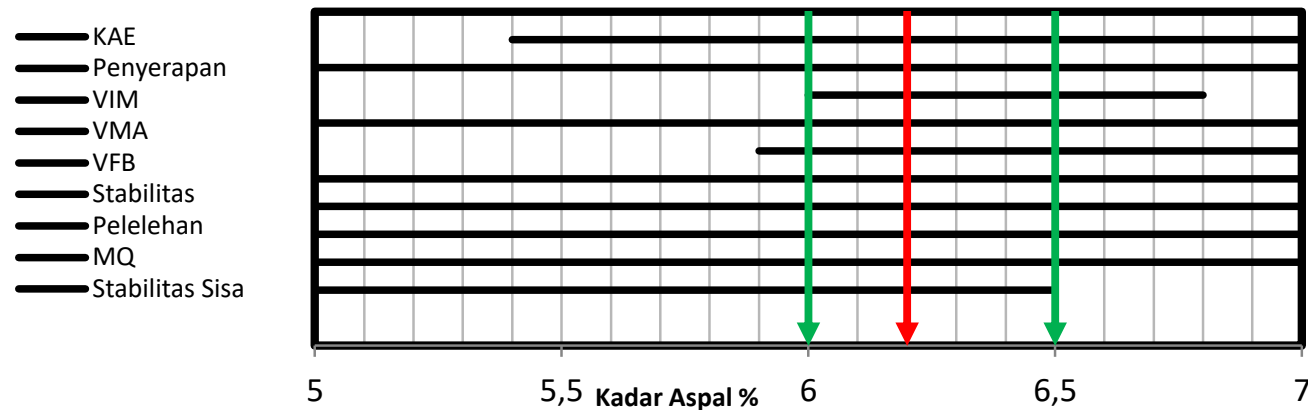

Figure 3 Determination of Composition 1 with asphalt KAO Asbuton LGA

Picture 3 above shows that in the range of $6.0 \%$ to $6.5 \%$ of the value - the value to all the requirements, so we get $\mathrm{KAO}$ at $6.2 \%$ in the composition of 1
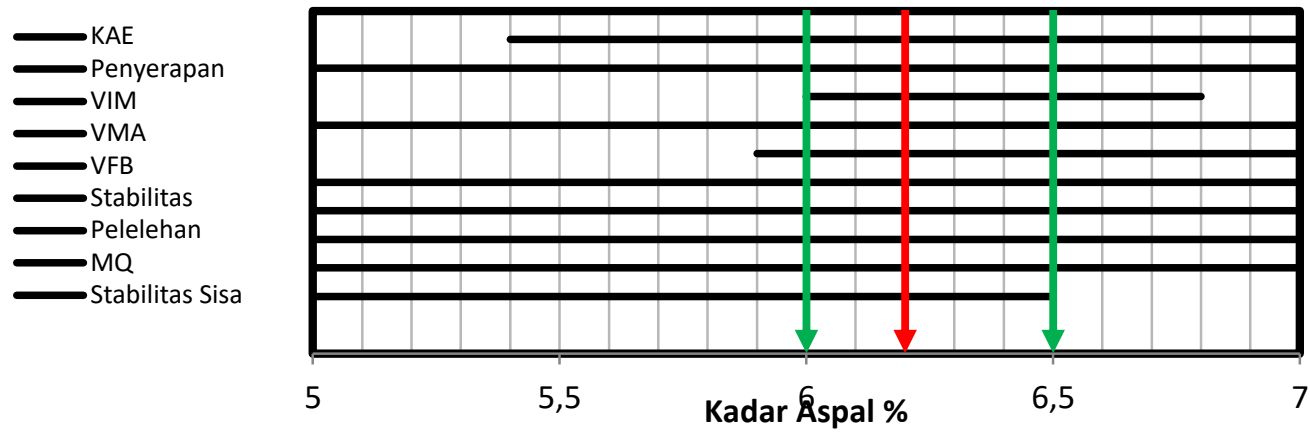

Figure 4 Determination of KAO Composition 2 with asphalt Asbuton LGA

Picture 4 above shows that in the range of $6.0 \%$ to $6.5 \%$ of the value - the value to all the requirements, so we get $\mathrm{KAO}$ at $6.3 \%$
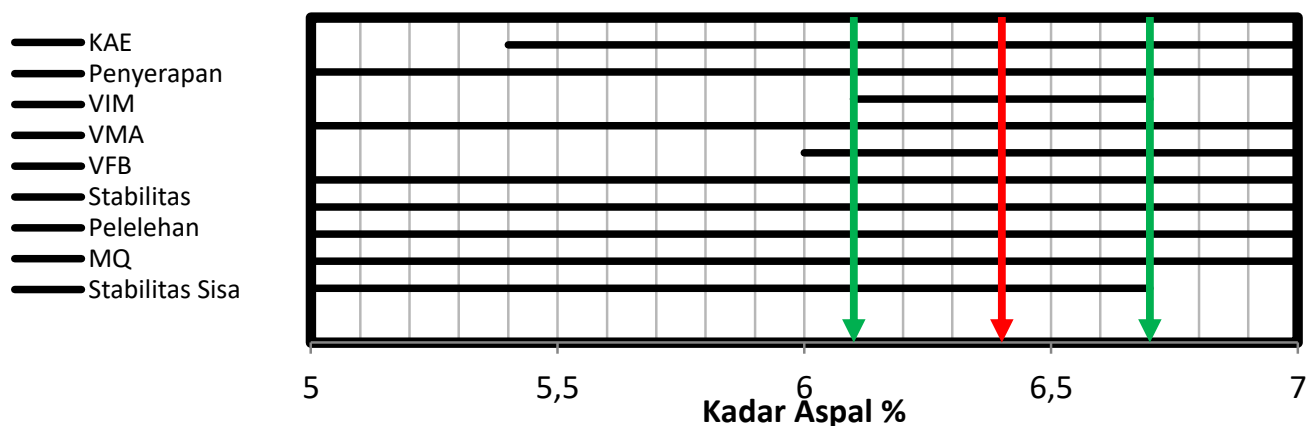

Figure 5 Determination of KAO Composition 3 with asphalt Asbuton LGA

Figure 5 The above shows that in the range of $6.1 \%$ to $6.7 \%$ of the value - the value to all the requirements in order to extract at $6.4 \% \mathrm{OBC}$,

From the test results of hot asphalt mixture of each composition used in this study, summarized the results in a graph for composition 1, composition 2 and the composition 3 , with the results of Figure 5 through Figure 14. 


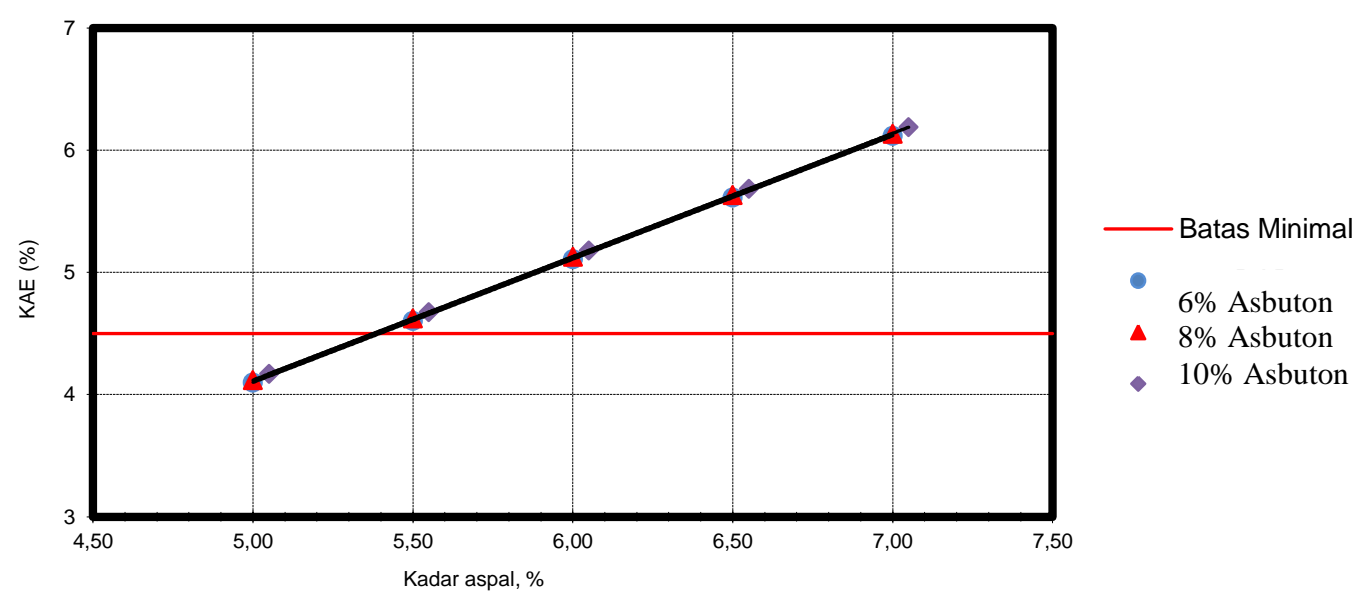

Figure 6. Levels Effective Asphalt Asphalt Asbuton

Figure 6 shows the value of bitumen content effective for hot asphalt mixtures with bitumen Asbuton LGA, growing with the increase in the percentage composition of the asphalt asbuton. The results of effective binder content value specifies the use asbuton $10 \%$ can improve the addition of asphalt content as well.

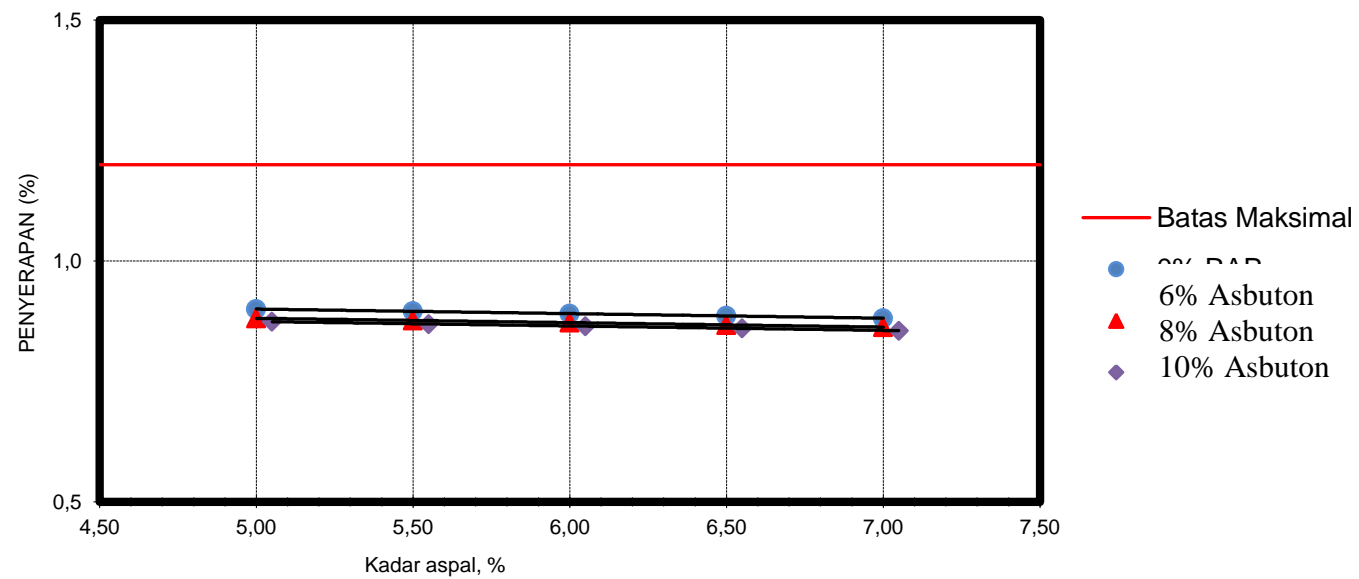

Figure 7. Absorption of Modified Asphalt Asbuton Processed

Picture 7 shows the absorption values for hot mix asphalt with asphalt Asbuton processed, shrink with the growing level of asphalt Asbuton LGA of $6 \%, 8 \%$ and $10 \%$.

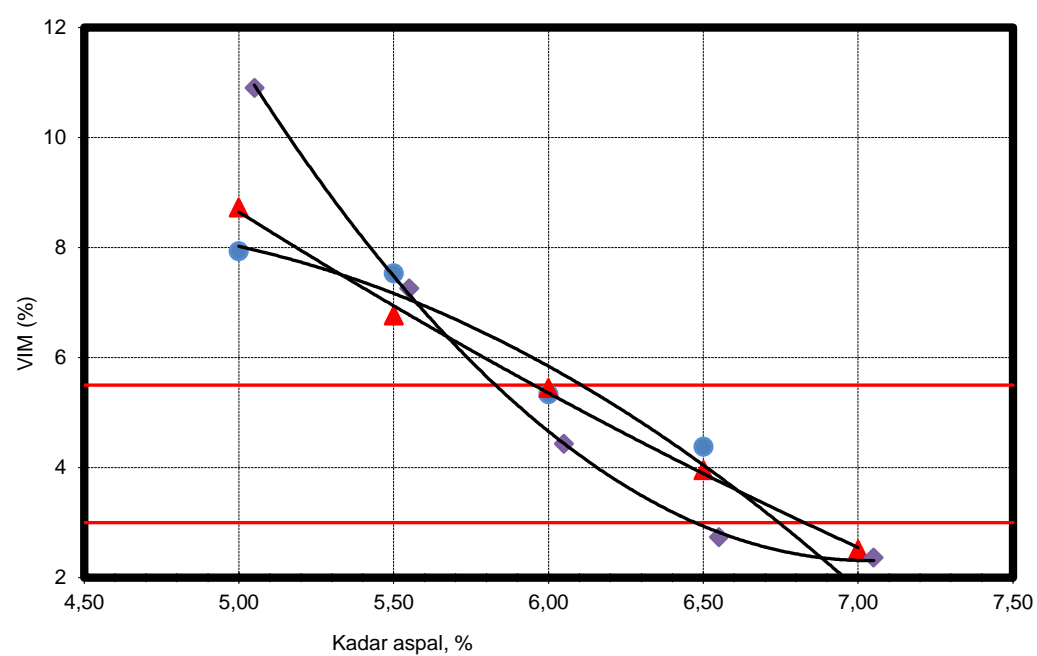

Figure 8. VIM Asphalt Asbuton

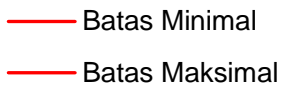

$6 \%$ Asbuton

8\% Asbuton

$10 \%$ Asbuton 
Picture 8 shows the value of the voids in the mix / voids in Mix (VIM) for hot asphalt mixture with modified bitumen processed Asbuton have value decreases with increasing addition of asbuton composition.

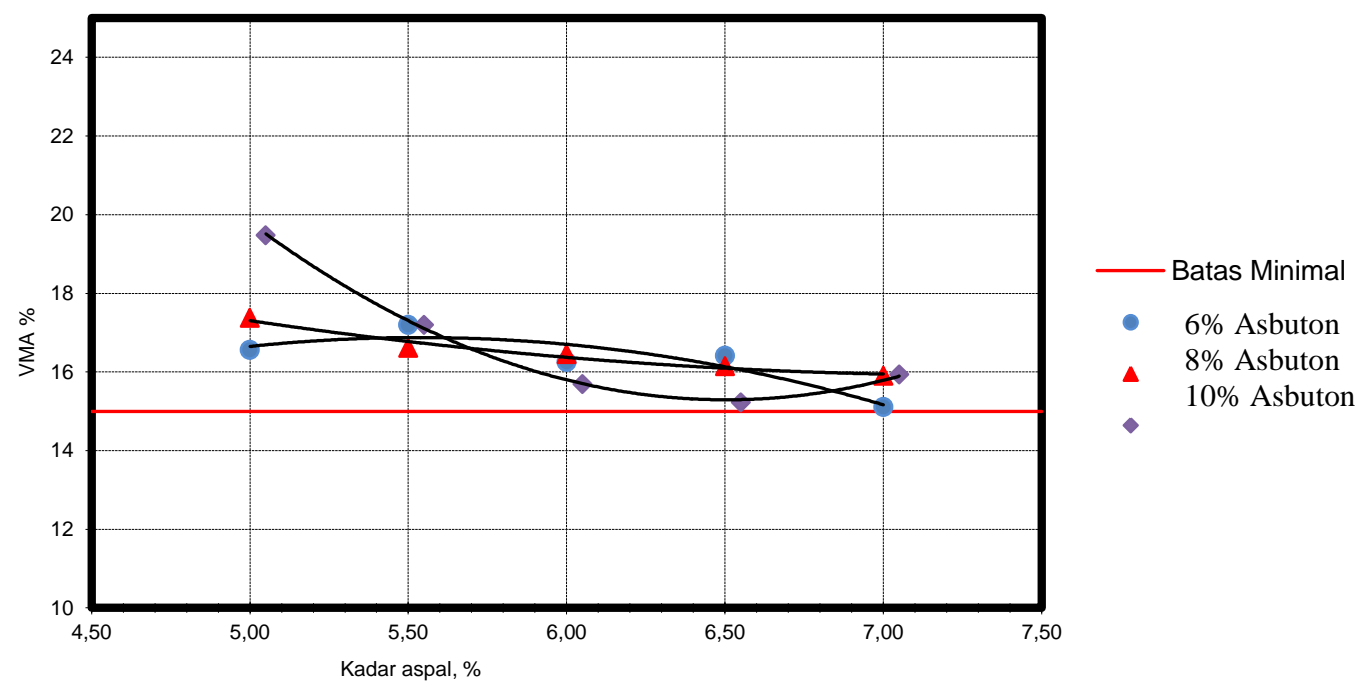

Figure 9 VMA Hot Asphalt Mixture with Asphalt Asbuton

Figure 9 shows the value VMA hot asphalt mixture with modified bitumen processed Asbuton decreases with increasing levels of Asphalt Asbuton.

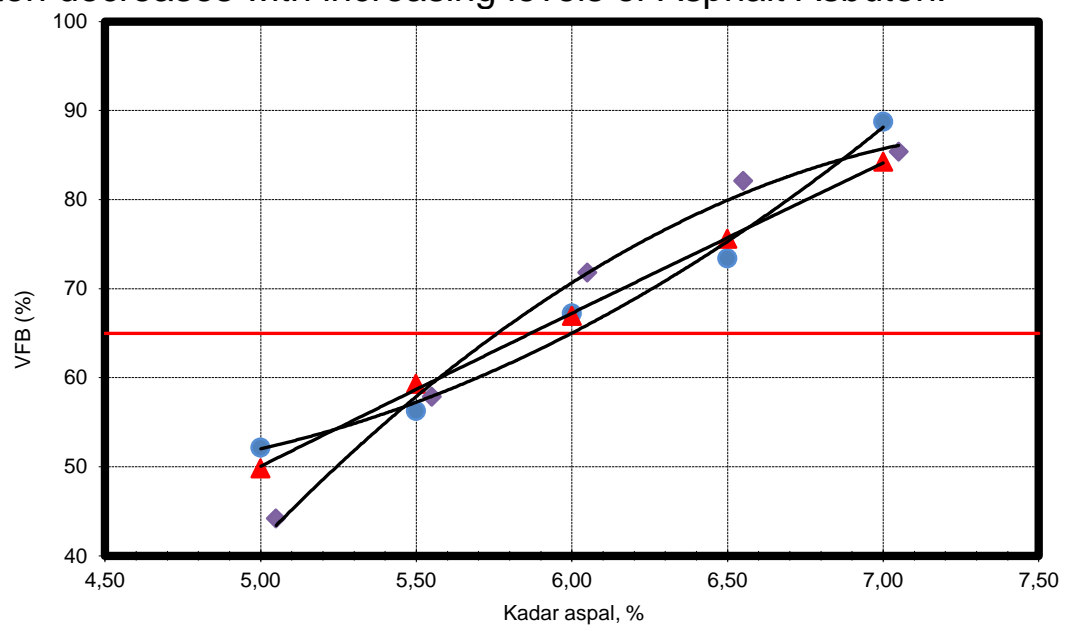

- Batas Minimal

$6 \%$ Asbuton

$8 \%$ Asbuton

$10 \%$ Asbuton

Figure 10. VFB Mixed With Asphalt Asbuton

Figure 10 shows the value VFB hot asphalt mixture with modified bitumen processed Asbuton enlarged with increased levels of Asphalt Asbuton. 


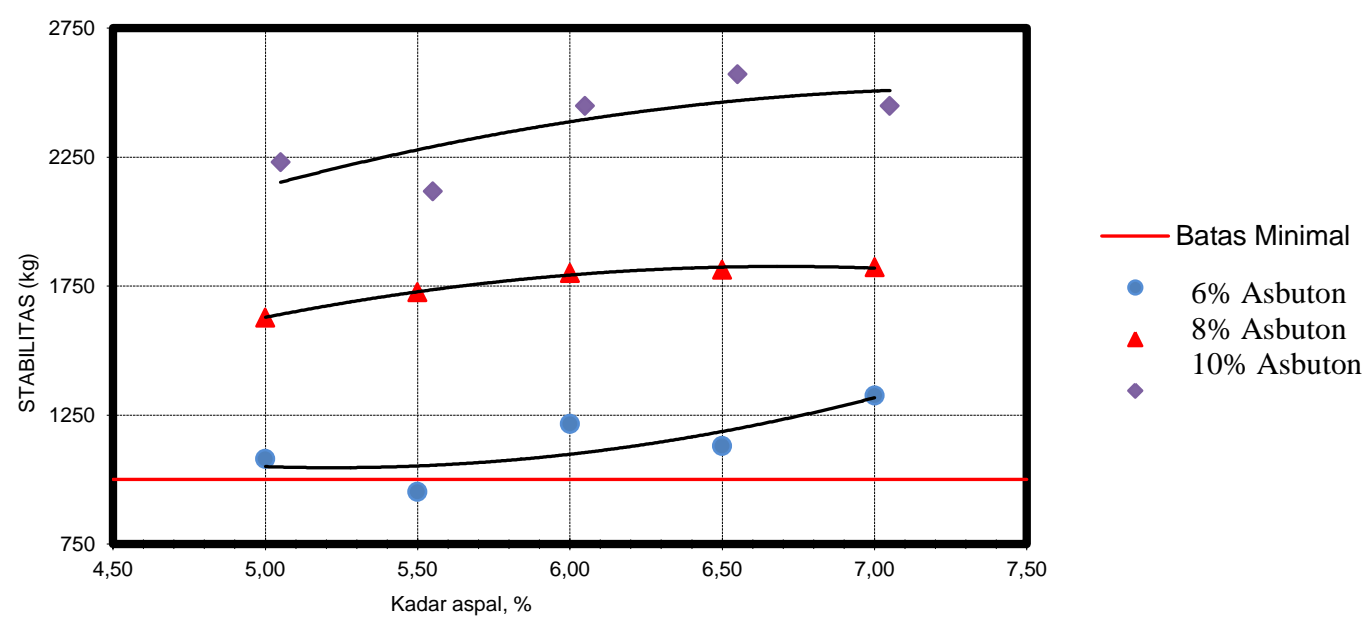

Figure 11.Asphalt Mixture Marshall stability with Asbuton

Picture 11 shows the value of a hot asphalt mixture Marshall stability with Asbuton enlarged with increased levels of Asphalt Asbuton.

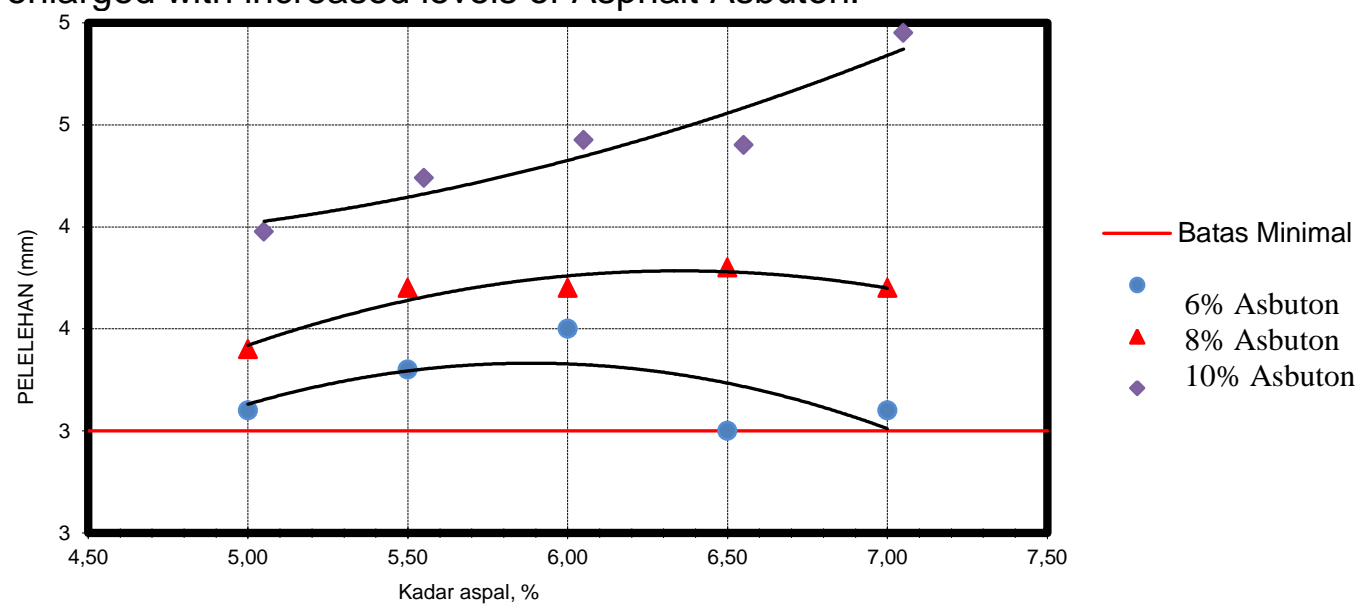

Figure 12. Melting Hot Asphalt Mixture with Asphalt Asbuton

Picture 12 shows the value of the heat melting asphalt mixture with Asbuton enlarged with increased levels of Asphalt Asbuton.

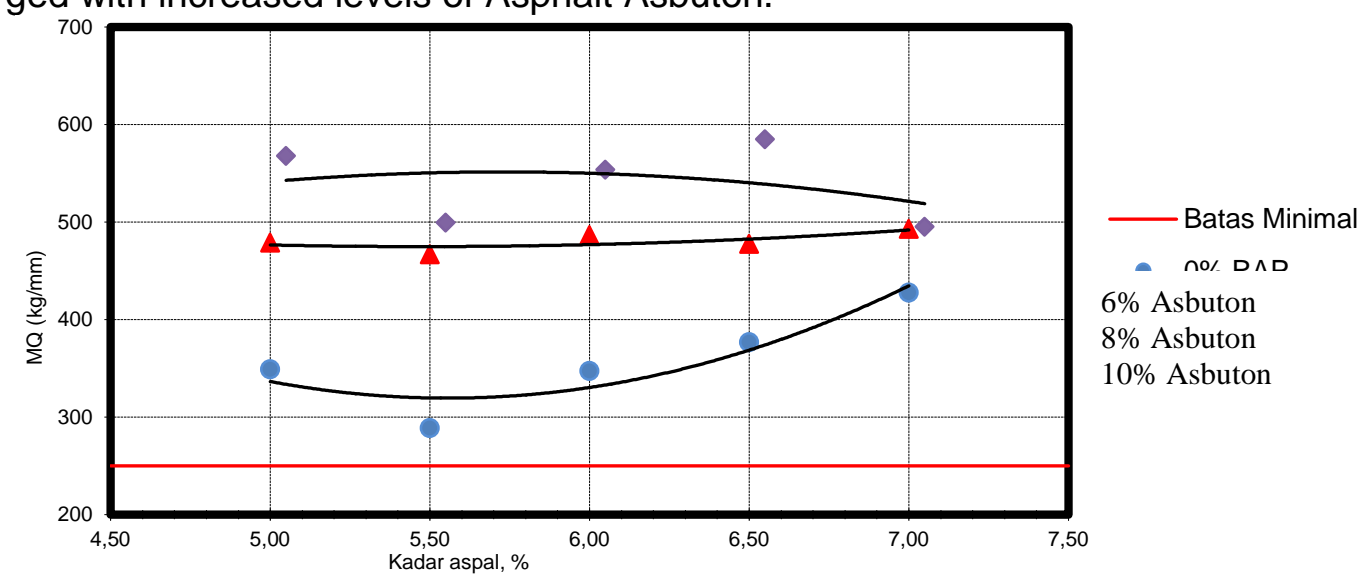

Figure 13. Marshall Quotient Hot Asphalt Mixture with Asphalt Asbuton 
Picture 13 shows the value of a hot asphalt mixture Marshall Quotient with Asbuton enlarged with increased levels of Asphalt Asbuton.
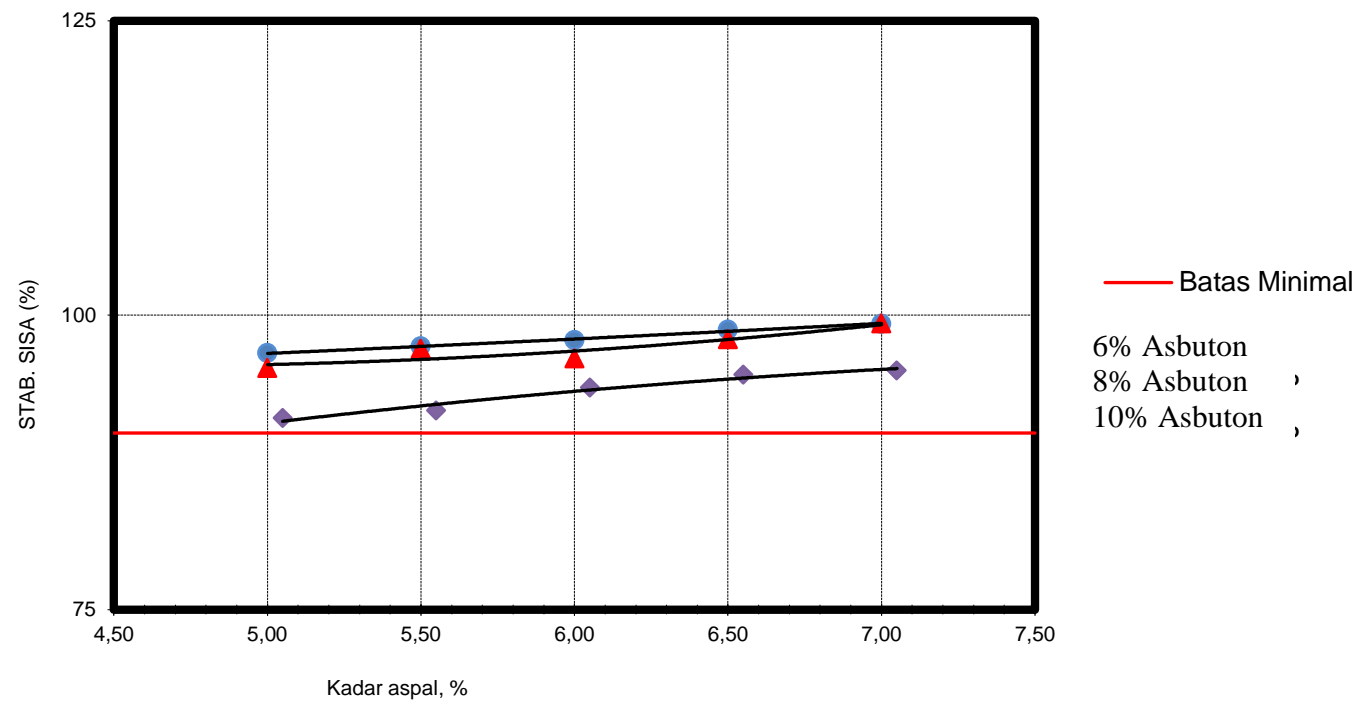

\section{$6 \%$ Asbuton}

$8 \%$ Asbuton $10 \%$ Asbuton ,

Figure 14.The rest of the Marshall stability Asphalt Mixture with Asbuton

Figure 14 shows the value of residual Marshall stability of hot asphalt mixture with Asbuton decreases with increasing levels of Asphalt Asbuton.

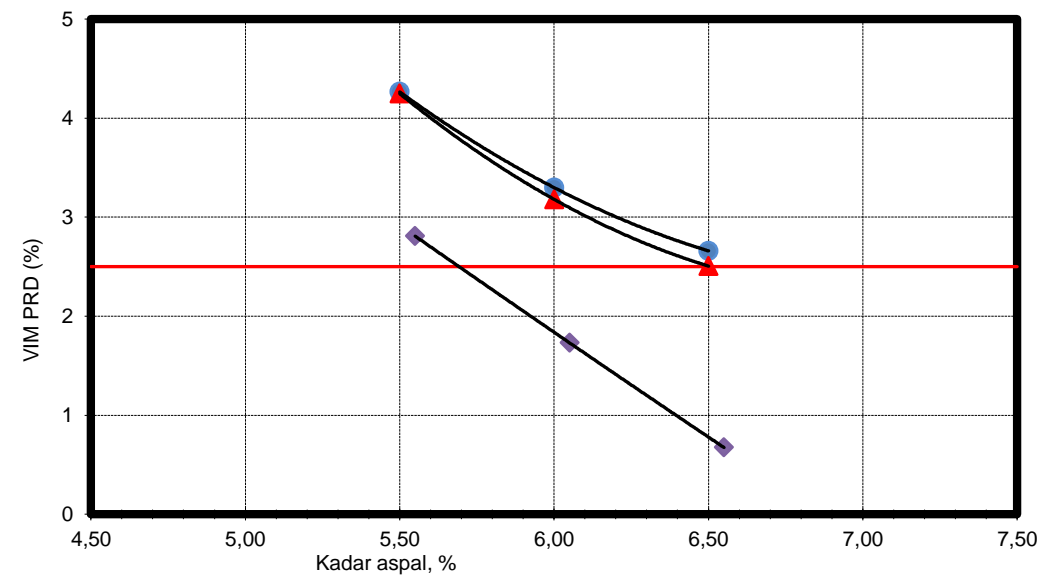

\section{- Batas Minimal}

$6 \%$ Asbuton

$8 \%$ Asbuton

$10 \%$ Asbuton $P$

Figure 15. VIM PRD Hot Asphalt Mixture with Asphalt Asbuton

Figure 15 shows the value of VIM PRD hot asphalt mixture with Asbuton decreases with increasing levels of Asphalt Asbuton.

1. Value Cavities In the Mix / voids in Mix (VIM) and Value cavity in the mix / voids in Mix (VIM) (\%) on the density bouncy / Percentage Refusal Density (PRD) for bitumen modification Asbuton that have value decreases with increasing levels of mixed composition. Likewise for Value Cavities In Aggregate / voids in Mineral Aggreggate (VMA). VIM cause a diminution of the value VMA value also decreases. Generally there is a tendency to increased levels of Asbuton with the declining value of the VMA, which is in part due to the low VIM.

2. Value Unfilled cavity Asphalt / voids Filled Bitumen (VFB) for bitumen modification has a value Asbuton processed enlarged with increased levels of Asbuton. VFB value is contrary to the values VIM (NAPA, 1996). This is in line with point $A$ above. 
3. Value Marshall stability for asphalt modification Asbuton processed and has a value of enlarged with increased levels of Asbuton, this is due to an increase in viscosity of asphalt mixture used according to Table 4:14. Increasing the viscosity of bitumen improves the stability Marshall (NAPA, 1996).

4. Value Melting for bitumen modification has a value Asbuton processed enlarged with increased levels of Asbuton. Melting high value indicates that the plastic mixture, it is likely due to the high viscosity and low penetration.

5. Value Dynamic stability for modified bitumen processed Asbuton has enlarged with increasing levels of value Asbuton, this is due to an increase in the value of the softening point of asphalt mixture used. This is in line with the increase in asphalt softening point decrease in the rate of plastic deformation, thus increasing the value of dynamic stability.

\section{CONCLUSION}

According research result, it can be concluded:

The test results for the optimum bitumen content KAO on the composition 1 Asbuton $6 \%$ with a variation of bitumen $(5.05 \% 5.55 \% 6.05 \% 6.55 \% 7.05 \%)$ of the chart can be found $\mathrm{KAO}$ Marshall $6.2 \%$. Composition 2 Asbuton $8 \%$ with a variation of asphalt (5.0\% 5.5\% 6.0\% 6.5\% 7.0\%) on the graph can be found KAO Marshall $6.3 \%$. Composition 3 Asbuton 10\% with a variation of asphalt (5.0\% 5.5\% 6.0\% 6.5\% 7.0\%) on the graph can be found KAO Marshall 6.4\%.Based on the results of laboratory tests, hot asphalt mixture AC-WC with additional Asbuton with variations of composition $6 \%, 8 \%$ and $10 \%$ meet all the requirements of the properties of hot asphalt mix can specification of Highways in 2018.

\section{REFERENCES}

AASHTO. (2014). Determining the fatigue life of compacted Hot Mix Asphalt (HMA) subjected to repeated flexural bending. Standard specifications for transportation materials and methods of sampling and testing Part 2B AASHTO $\mathrm{T}$ 321-14, Washington, DC: American Association of State Highway and Transportation Officials.

American Society for Testing and Materials (ASTM). (1995). Standard Test Method for Indirect Tension Test for Resilient Modulus of Bituminous Mixtures D4123-82, In ASTM International (Ed.), West Conshohocken.

DGH. (2018). General Specifications Year 2018. Highways Directorate General of Highways, Ministry of Public Works. Jakarta.

Budianto, Herrera (2009), Towards Reliable Way, Cakra Daya Sakti, Surabaya.

National Asphalt Pavement Association (1996), Hot Mix Asphalt Materials, Mixture Design, and Construction, NAPA Education Foundation, Maryland.

The Government of the Republic of Indonesia (2004), the Law of the Republic of Indonesia Number 38 Year 2004 on the road, the Government of the Republic of Indonesia, Jakarta

The Government of the Republic of Indonesia (2004), the Law of the Republic of Indonesia Number 38 Year 2004 on the road, the Government of the Republic of Indonesia, Jakarta

Sukirman, S. (1992), Planning Pavement Structure Thickness, NOVA, Bandung.

Sukirman, S. (1999) Flexible Pavement Road. Bandung: Publisher Nova.10.

Sukirman, S. (2003) Hot Mix Asphalt Concrete. Jakarta: Granite. 